\title{
A oferta de ensino superior por Universidades Federais no interior da Amazônia: da UFPA à UFOPA em Santarém-PA/Brasil
}

\author{
Nilzilene Gomes de Figueiredo'
}

\section{RESUMO}

Tem-se por objetivo fazer uma reconstituição histórica da oferta do ensino superior na Amazônia brasileira e compreender o processo de interiorização das Instituições Federais de Ensino Superior (IFES) nessa região no período de 1970 a 2009, em especial em Santarém, oeste do Pará. Ampara-se em teses, dissertações, artigos, documentos oficiais e reportagens de jornais da década de 90 que retratam 0 cenário. Percebe-se que a UFPA foi pioneira na oferta do ensino superior na Amazônia brasileira quando surge em Belém em 1957 e influenciou fortemente outros estados no processo de expansão de seus cursos para o interior (interiorização). A chegada do ensino superior a nível de graduação em Santarém surge com cursos oferecidos pela UFPA no início da década de 70, mas se tornou mais efetiva quando os projetos de interiorização da UFPA oportunizaram a criação de um campus universitário em Santarém em 1986, o que levou à formação de muitos profissionais na região, em especial de professores cuja demanda no Pará era alarmante naquele período, o que perdurou ainda por muitos anos. A luta histórica das comunidades locais por ensino superior público de qualidade e políticas desenvolvimentistas do governo federal para o ensino superior tanto permitiram a consolidação dos cursos da UFPA em Santarém quanto impulsionaram a criação de uma instituição federal com sede em Santarém em 2009, a Universidade Federal do Oeste do Pará (UFOPA), que deu continuidade à formação de profissionais na região, alcançando uma demanda muito maior de estudantes de todo o oeste do Pará.

Palavras-chave: Ensino Superior. Amazônia. Instituições de Ensino. Política de Desenvolvimento.

\section{The offer of higher education by Amazonian countryside Federal Universities:}

\section{from UFPA to UFOPA in Santarém-PA/Brazil}

\begin{abstract}
This work has as objective to make a historical reconstruction of higher education offer in Brazilian Amazon and understand the process of internalization of Federal Institutions of Higher Education (IFES) in the region from 1970 to 2009, especially in Santarem, west of Pará. It is supported by theses, dissertations, articles, official documents, and newspaper reports from the 90's which portray the scenario. It is

1 Doutorado em Educação. Professora do Intituto de Ciências da Educação da Universidade Federal do Oeste do Pará, Santarém, Pará, Brasil. Orcid iD: https://orcid.org/0000-0003-30727035. E-mail: nilzileneufopa@gmail.com
\end{abstract}


observed that UFPA was a pioneer in offering higher education in the Brazilian Amazon when it appeared in Belem in 1957 and strongly influencing other states in the process of expanding its courses to the inside (interiorization). The arrival of higher education at the undergraduate level in Santarem, which emerged as courses offered by UFPA in the early 1970s, but which became more effective when the interior design projects at UFPA, which led to the creation of a university campus in Santarem in 1986, which helped to train many professionals in the region, especially teachers whose demand in Pará was alarming at that time, which lasted for many years. The historic struggle of local communities for public higher quality education and development policies of the federal government for higher education both allowed the consolidation of UFPA courses in Santarém as promoted the creation of a federal institution based in Santarém in 2009, the University Federal west of Pará (UFOPA), which continued the training of professionals in the region, reaching a much greater demand for students from all over the west of Pará.

Keywords: Higher Education. Amazon. Educational Institutions. Development Policy.

\section{Expansión de las Universidades Federales a la Amazonía: de UFPA a UFOPA en Santarém-PA/Brasil}

\section{RESUMEN}

El objetivo de este manuscripto es hacer un rescate histórico sobre la oferta de educación superior en Amazonía brasileña y comprender el proceso de expansión de las Instituciones Federales de Educación Superior (IFES) para esta región, es decir, el proceso de internalización, desde 1970 hasta 2009, especialmente en Santarém, oeste de Pará. El manuscripto se ampara en tesis, tesinas, artículos, documentos de UFPA y informes obtenidos en periódicos década de los 90. Se puede ver que UFPA fue pionera en ofrecer educación superior en la Amazonía brasileña cuando apareció en Belém en 1957 e influyó fuertemente en otros estados en el proceso de expansión de sus cursos hacia el interior (interiorización). La llegada de la educación superior a nivel de grado en Santarém viene con cursos ofrecidos por UFPA a principios de la década de 1970, pero se hizo más efectiva cuando los proyectos de interiorización de UFPA hicieron posible crear un campus universitario en Santarém en 1986, que condujo La capacitación de muchos profesionales en la región, especialmente docentes cuya demanda en Pará era alarmante en ese momento, que duró muchos años. La pelea histórica de las comunidades locales por la educación superior pública de calidad y las políticas desarrollistas del gobierno federal para la educación superior permitieron la consolidación de los cursos de la UFPA en Santarém e impulsaron la creación de una institución federal con sede en Santarém en 2009, UFOPA, que continuó capacitando profesionales en la región, alcanzando una demanda mucho mayor de estudiantes de todo el oeste de Pará.

Palabras clave: Educación Superior. Amazon. Instituciones Educativas. Políticas de Desarrollo. 


\section{Introdução}

No cenário internacional a educação superior é considerada um bem público e as universidades têm sido reconhecidas ao longo da história do Brasil como importantes instrumentos de transformações sociais e possibilidade do país se inserir de forma competente nesse cenário (BRASIL, 2012). Esse reconhecimento levou ao longo da história a movimentos reivindicatórios por educação superior pública e gratuita em diversas localidades do país, em especial na região Amazônica. O acesso ao ensino superior nessa região brasileira deu um salto quantitativo nas últimas três décadas, fruto do aumento significativo no número de instituições, matrículas e abertura de novos cursos (LIMA, 2015), mas essa realidade era muito diferente há algumas décadas atrás.

Até por volta da década de 30 do século XX as instituições de ensino superior brasileiras estavam concentradas nas regiões hoje conhecidas como Sul e Sudeste do país. O ensino superior na Amazônia brasileira, mesmo nas capitais dos Estados, ainda era insignificante, o que começa a sofrer um processo de mudança a partir das Reformas do Ensino Superior que chegam à região Amazônica tanto na década de 30 quanto na década de $60 \mathrm{com}$ o slogan de "progresso" e "desenvolvimento".

Mais particularmente quanto ao Estado do Pará, a chegada das Instituições Federais de Ensino Superior (IFES) passou a desencadear uma série de ações que mudaram em muitos aspectos os modos de vida das populações locais. Para compreendermos melhor como se deu a chegada dessas instituições no interior do Pará e os ideais desse movimento, temos como objetivo fazer um resgate histórico sobre a oferta do ensino superior na Amazônia e compreender o processo de interiorização das IFES nessa região, e mais particularmente no Pará, que pode ser considerado pioneiro através de ações da Universidade Federal do Pará (UFPA). Será dado destaque para a chegada do ensino superior em Santarém e à influência na vida das pessoas dessa região.

A pesquisa tem enfoque qualitativo e ampara-se em um estudo de caso, que consiste "na observação detalhada de um contexto, ou indivíduo, 
de uma única fonte de documentos ou de um acontecimento específico" (MERRIAM, 1988 apud BOGDAN; BIKLEN, 1994, p. 89). A estratégia de pesquisa se configura como um estudo de caso único (YIN, 2001). Ponte (2006) nos esclarece que o estudo de caso investiga situações específicas para a compreensão global do fenômeno que se pretende analisar.

É uma investigação que se assume como particularística, isto é, que se debruça deliberadamente sobre uma situação específica que se supõe ser única ou especial, pelo menos em certos aspectos, procurando descobrir o que há nela de mais essencial e característico e, desse modo, contribuir para a compreensão global de um certo fenômeno de interesse (PONTE, 2006, p. 2).

Assim, podemos dizer que ele difere de outros tipos de pesquisa por se propor a compreender uma instância singular, que é multidimensional e historicamente situada (LUDKE; ANDRÉ, 1986). Além disso, o poder diferenciador do estudo de caso é possuir "a capacidade de lidar com uma ampla variedade de evidências - documentos, artefatos, entrevistas e observações" (Ibidem, p.18), procurando a triangulação de dados nelas contidos.

Nesse caso, focamos na história da expansão da UFPA para compreender o processo de expansão das Universidades Federais na Amazônia. Para a construção da narrativa histórica apresentada neste artigo foram consultadas duas teses de Doutorado (COSTA, 2014; CARVALHO, 2014), duas dissertações de mestrado (VASCONCELOS, 2007; GOMES, 2011), artigos que tratavam sobre o Ensino superior na Amazônia e sobre a história dos projetos de interiorização da UFPA (MORAES, 1992; DIAS; COELHO; SANTOS, 2004; BARBOSA; LOPES, 2010; FONTES, 2012; LIMA, 2015; NASCIMENTO, 2016), reportagens de dois jornais impressos que circulavam por Santarém-PA no período de 1988 a 1994 (Jornal de Santarém e O Tapajós) que traziam reportagens sobre o processo de interiorização da UFPA em Santarém, documento de transformação do campus da UFPA/Santarém em Centro Universitário Federal do Tapajós (UNIVERSIDADE FEDERAL DO 
PARÁ, 2000), textos de sítios institucionais da Universidade Federal do Pará e da Federal do Oeste do Pará (UFOPA).

\section{Os programas federais brasileiros para expansão das IFES}

Curiosa e contraditoriamente as duas principais reformas do ensino superior que acabaram por impulsionar a criação de IFES na Amazônia ocorreram em períodos de regimes autoritários (Reforma de 1930 no início do primeiro período do Governo Vargas, e Reforma de 1968 durante o Regime militar), amparadas na euforia da ideologia desenvolvimentista (COSTA, 2014; DIAS; COELHO; SANTOS, 2004).

Tão logo Vargas assumiu o poder, criou o Ministério da Educação e Saúde Pública (MES) - Decreto n 19.402, de 14/11/1930 - e nomeou Francisco Campos para assumi-lo. A criação do MES foi uma das primeiras medidas do Governo provisório de Vargas para fazer com que o Estado Nacional tomasse ações mais objetivas para solucionar os problemas educacionais do país, já que até aquele momento inexistia uma política Nacional de Educação a qual os sistemas educacionais estivessem subordinados.

Assim, a Reforma Campos, como ficou conhecida, proposta para os vários níveis de ensino, pela primeira vez na história da Educação brasileira visava atingir o Brasil como um todo (MORAES, 1992) e a região Amazônica é pensada pela primeira vez como integrante de um Estado Nacional (ARBEX JUNIOR, 2005 apud COSTA, 2014).

Dentre os vários decretos que formaram a Reforma Campos, o decreto $n^{\circ} 19.851$ de 11/04/1931 estabeleceu as Diretrizes para o ensino superior e instituiu o regime universitário para essa modalidade de ensino (MORAES, 1992; VASCONCELOS, 2007). Até aquele momento, o ensino superior no Brasil havia sido organizado de forma heterogênea, através de faculdades ou escolas em diferentes Estados, sem o Governo federal ter feito um planejamento ou gerenciamento (VASCONCELOS, 2007).

Em termos de política pública, percebemos que houve avanço representado por essa Reforma referente ao ensino superior, mas ela não 
deixou de ser uma forma de tentar garantir a centralização de decisões que foi característica do governo Vargas. Em suas análises sobre o decreto, Moraes (1992, p. 292) ressalta que "a universidade foi concebida mais como um instrumento político do que como um espaço para a produção científica".

A partir desse período a educação superior cresceu lentamente para o resto do Brasil, mas foi na década de 50, quando o país apresentava aceleração no ritmo de desenvolvimento, aumento do número de concluintes do ensino secundário devido à expansão desse nível, dentre outros fatores, que as cobranças populares visando maior quantidade de vagas no nível superior impulsionaram a criação de novas Universidades.

A promulgação da lei $n^{\circ} 1.254$, de 4 de dezembro de 1950 cria 0 Sistema Federal Superior ${ }^{2}$ que reúne instituições que funcionavam de formas diversas no oferecimento desse nível de ensino. Elas passaram a ser incorporadas às novas Universidades Federais que então surgiam. Esse movimento ficou conhecido como Federalização das escolas isoladas. Costa (2014, p.153) ressalta que "com a federalização o Governo esperava o reconhecimento do valor implícito de se ter a presença da União nas Universidades Federadas de todo o país". Nessa efervescência do processo expansionista são criadas as primeiras IFES na Amazônia.

A região Amazônica não somente naquela época, mas ainda hoje é considerada de muitas belezas naturais, e especialmente no início do século XX também era reconhecida como atrasada e inóspita; acredita-se que em decorrência do atraso cultural "resultante da baixa possibilidade de acesso ao conhecimento científico e tecnológico" (COSTA, 2014, p. 176). Considerando essa necessidade, muitos projetos de infraestrutura foram implementados sob a justificativa do "progresso" e do "desenvolvimento", mas que não levavam em consideração, muitas vezes, a realidade amazônica.

O resultado desse contexto foi o "agravamento da pobreza, em

2 Essa lei foi modificada em alguns aspectos pela Lei nº 2337 de 20/1 1/1954. 
especial das populações mais atingidas diretamente pelas transformações ocorridas devido a exploração de recursos naturais e sem planejamento adequado" (UNIVERSIDADE FEDERAL DO PARÁ, 2000). Tal situação gerou reflexos negativos que podem ser sentidos ainda hoje, tanto em termos sociais, quanto econômicos e ambientais. Apesar dessas controvérsias, a chegada do ensino superior público na região trazia uma nova esperança de melhorias nas condições de vida para as comunidades locais, pois passou a ser vista como possibilidade de desenvolvimento econômico e social (DIAS; COELHO; SANTOS, 2004).

Registros mostram que entre os anos 60 e 70 do século XX universidades vindas do Sul e Sudeste já realizavam ações extensionistas no interior dos estados amazônicos através da instalação de campi avançados, incentivados pelo programa de mesmo nome aprovado pelo Ministério da Educação (MEC), em 1969, em virtude da evolução institucional do Projeto Rondon ${ }^{3}$. Essas universidades, como foi o caso da Universidade Federal de Santa Catarina (UFSC), realizavam projetos de desenvolvimento comunitários e programas de qualificação em pequena escala, mas não eram suficientes para atender a demanda de ensino superior, principalmente devido ao crescimento populacional e baixos índices de capacitação de pessoal na região (COSTA, 2014).

As primeiras Universidades Federais criadas na região Amazônica, resultantes do processo de expansão das IFES, estão localizadas no Estado do Pará: em 1945 a Faculdade de Ciências Agrárias do Pará (FCAP) e em 1957 a Universidade do Pará, que depois foi chamada de Universidade Federal do Pará (UFPA); ambas fundadas em Belém, capital do Estado paraense. Apesar de a FCAP ter sido criada em 1945, ela só passa a crescer e se tornar permanente na região após a presença das IFES na Amazônia

\footnotetext{
3 Projeto Rondon: Projeto de extensão universitária criado durante o regime militar no Brasil. Levava estudantes para regiões mais isoladas do país para promoverem ações extensionistas com a justificativa de contribuir para o desenvolvimento sustentável de comunidades carentes e ampliação do bem-estar da população. O projeto perdurou de 1967 a 1989, mas foi relançado em 2005 pelo Governo Federal por solicitação da União Nacional dos Estudantes (UNE). Para detalhes consulte a página oficial do projeto: https://projetorondon.defesa.gov.br/portal/index
} 
(lbidem) ${ }^{4}$.

A UFPA, além de pioneira, tornou-se uma das mais importantes IFES do Norte do país. Ela foi criada através da Lei n 3191 de 02/07/1957 sancionada pelo presidente Juscelino Kubitschek, após tramitação de cinco anos na Câmara Legislativa. A nova instituição agregou sete faculdades federais, estaduais e privadas existentes na capital do Pará: Medicina; Direito; Farmácia, Engenharia, Odontologia, Filosofia, Ciências e Letras, Ciências Econômicas, Contábeis e Atuariais5.

No entanto, estudos como os de Costa (2014) e Dias, Coelho e Santos (2004) mostram que até a segunda metade do século XX o ensino superior no Pará inexistia para grande parte da população paraense, pois a oferta de vagas estava concentrada na capital (Belém), como ocorria com outros estados amazônicos. Cerca de $75 \%$ da população paraense nessa época residia fora da capital, o que significa dizer que a grande maioria dos jovens estava à margem da oferta de ensino superior (UFPA, 2000), já que pelas condições financeiras da maioria das famílias, era pouco provável que conseguissem estudar na Capital. Assim, a demanda para o nível superior atingia números gigantescos, especialmente se comparada esta oferta com a de outros Estados brasileiros do Sul e Sudeste, reforçando o cenário de exclusão educacional, que também acontecia em outros níveis de ensino no Estado do Pará.

Tal situação durou pelo menos até a década de 70, quando ocorreu a disseminação do ensino superior para os principais polos de desenvolvimento do Estado, impulsionados principalmente por dois fatores: a nova Reforma do ensino superior efetivada pelo ministro da Educação Tarso Dutra durante o regime militar no Brasil, através da Lei n 5.540 de 28/11/1968, e pressões da sociedade civil organizada do interior paraense motivadas pelas enormes necessidades sociais e educacionais (COSTA, 2014).

Em nível nacional, a própria criação da Lei n $5.540 / 68$ foi em grande

\footnotetext{
${ }^{4}$ A FCAP tornou-se Universidade Federal Rural da Amazônia (UFRA) em 23/12/2002, pela Lei $n^{\circ} 10.611$.

5 Informação disponível no site da UFPA: https://portal.ufpa.br/index.php/universidade. Acesso: 13 jan. 2020.
} 
parte resultado da luta histórica de resistência cívica de estudantes e professores brasileiros, especialmente na década de 60 (BARBOSA; LOPES, 2010). Martins (2009) destaca que de 1967 a 1980 as matrículas no ensino superior público passaram de 88 mil para aproximadamente 500 mil no Brasil, com crescimento da ordem de $453 \%$, mas ainda estava muito aquém das necessidades de acesso ao ensino superior, o que abriu "um flanco favorável à participação do ensino privado" (p.22), como ressalta o autor.

Dados do MEC indicam que até o final de 2002 "o ensino superior público federal já contava com 45 universidades federais e 148 campi/unidades" (BRASIL, 2012. p. 9). A figura 1, apesar de não mostrar todos os campi indicados nesse documento, mostra como as IFES estavam espalhadas pelo Brasil nesse período.

Podemos observar pelo mapa que a maior parte das instituições federais no ano 2000 ainda se concentrava, principalmente, no Sul e Sudeste do Brasil e apenas 10 estavam localizadas na Amazônia legal. Mas dados do relatório de gestão da UFPA do ano de 2000 indicam que nessa ocasião a instituição já contava com 09 campi universitários espalhados pelo interior do estado situados em Abaetetuba, Breves, Cametá, Soure, Castanhal, Bragança, Marabá, Altamira e Santarémb.

6 Fonte: https://proplan.ufpa.br/images/conteudo/proplan/dinfi/relatorio\%20de\%20gestao/Relat_Gestao_2001.pdf. Acesso em: 09 mai. 2020.

Revista Exitus, Santarém/PA, Vol. 10, p. 01-30, e020098, 2020. 
Figura 1 - Cenário brasileiro das Instituições Federais do Ensino Superior (IFES) até 2002, anterior à expansão. Destaque da Amazônia legal com suas 10 instituições

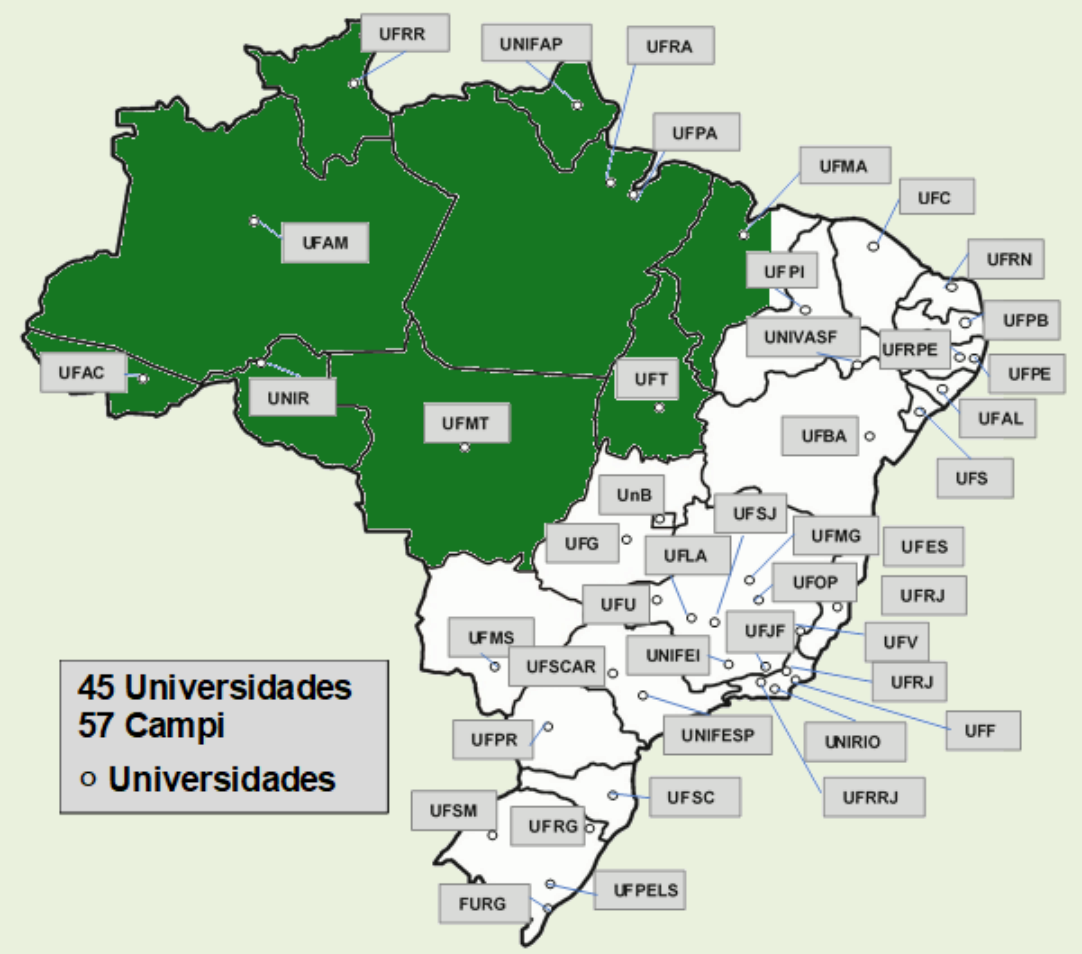

Fonte: Inspirado em Maculan (2006), com adaptações.

O Plano Nacional de Educação - PNE (2001-2010) -, para dar cumprimento ao que previa a Constituição de 1988 da "educação como direito de todos e dever do Estado e da família", previu um aumento considerável de investimentos no ensino superior e ampliação no número de estudantes matriculados. Por esse documento, a meta era expandir a oferta do ensino superior até o fim da década para, pelo menos, $30 \%$ dos jovens entre 18 e 24 anos (BRASIL, 2012).

Assim, para pôr em prática o previsto no PNE, foram criados os Programas de expansão do ensino superior. A primeira fase do Programa, denominada Expansão I (2003-2007), teve como principal meta interiorizar o ensino superior público federal. Em 2007 foi criado o Programa de Apoio a Planos de Reestruturação e Expansão das Universidades Federais (REUNI) por meio do decreto $n^{\circ}$ 6.096/2007 e tinha como principal meta

(...) criar condições para a ampliação do acesso e permanência no ensino superior, no nível de graduação presencial, pelo melhor aproveitamento da estrutura física e de recursos humanos existentes 
nas universidades federais. Também havia possibilidade de criação de novos câmpus para o interior do país, de acordo com o Plano de Desenvolvimento Institucional (PDI) das universidades federais (BRASIL, 2012, p. 10).

Ao mesmo tempo em que o REUNI foi criado, também ocorreu uma fase chamada pelo MEC de Integração regional e internacional. Nessa fase foram criadas quatro universidades com seus propósitos assim definidos:

\begin{abstract}
Universidade Federal da Fronteira Sul (UFFS), que integra os estados fronteiriços da região Sul do Brasil; Universidade Federal do Oeste do Pará (Ufopa), que é a universidade de integração amazônica; Universidade Federal da Integração Latino-Americana (Unila), voltada para todos os países da América Latina; e a Universidade de Integração Internacional da Lusofonia Afro-Brasileira (Unilab), cujo objetivo é a aproximação entre os países falantes da língua portuguesa em outros continentes, como a África e Ásia (BRASIL, 2012, p. 11).
\end{abstract}

O REUNI representou uma tentativa do governo de atender a reivindicações e anseios da sociedade para a ampliação de vagas no ensino superior (BRASIL, 2012). Observa-se que a criação da Universidade Federal do Oeste do Pará (UFOPA) surge como resultado desse processo, mas há outros antecedentes históricos regionais importantes para a criação dessa nova universidade no interior da Amazônia, como veremos adiante.

Como resultado desse programa de expansão das IFES, a ampliação do número de instituições e vagas foi considerável de 2003 a 2010, como podemos ver na tabela 1 , em especial no número de municípios atendidos e número de vagas.

Tabela 1 - Crescimento do número de Instituições Federais de Ensino Superior (IFES), municípios atendidos e número de vagas no Brasil entre 2003 e 2010

\begin{tabular}{|c|c|c|c|}
\hline & 2003 & 2010 & Crescimento \\
\hline IFES & 45 & 59 & $31 \%$ \\
\hline Campus & 148 & 274 & $85 \%$ \\
\hline $\begin{array}{c}\text { Municípios } \\
\text { atendidos }\end{array}$ & 114 & 272 & $138 \%$ \\
\hline Número de vagas & 109.184 & 231.530 & $112 \%$ \\
\hline
\end{tabular}

Fonte: Brasil (2012).

Observando a linha do tempo da criação das universidades federais no 
País no gráfico 1, percebe-se que entre 2003 e 2010, como fruto desses programas, ocorreu a criação do maior número de universidades (14).

Gráfico 1 - Linha do tempo da criação das Universidades federais

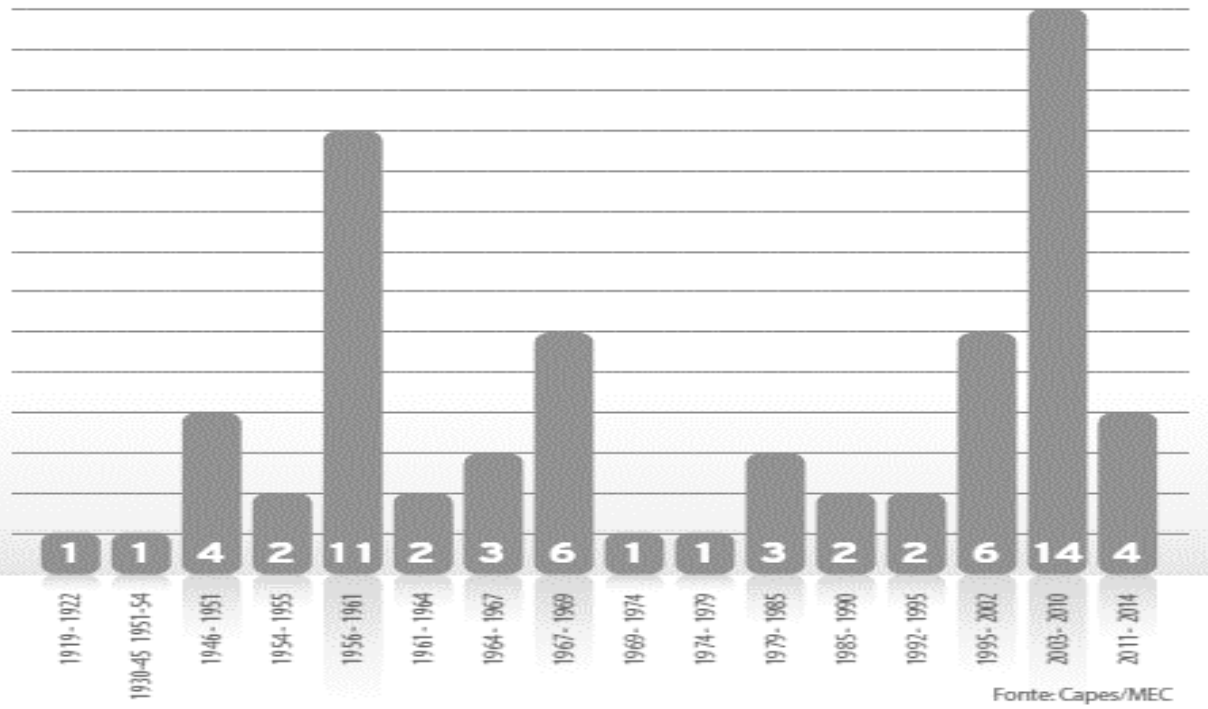

Fonte: Brasil (2012).

Em 2012 a região Norte do Brasil, que corresponde à maior parte da Amazônia legal, já possuía 56 municípios atendidos por 10 universidades federais7: UFAC (Universidade Federal do Acre), UFAM (Universidade Federal do Amazonas), UFOPA (Universidade Federal do Oeste do Pará), UFPA (Universidade Federal do Pará), UFRA (Universidade Federal Rural da Amazônia), UFRR (Universidade Federal de Roraima), UFT (Universidade Federal do Tocantins), UNIFAP (Universidade Federal do Amapá), UNIFESSPA (Universidade Federal do Sul e Sudeste do Pará) e UNIR (Fundação Universidade Federal de Rondônia), segundo dados do Brasil (2012, p. 44). Além da importância no investimento do governo federal para a expansão das IFES pela Amazônia, em muito esse resultado se deve aos projetos de interiorização das universidades do Norte do país, com pioneirismo da UFPA, que trataremos na próxima seção.

\footnotetext{
7 No mapa da figura 1 podemos observar que 8 universidades federais faziam parte da região Norte antes de 2002, localizadas nos estados do Acre, Amazonas, Roraima, Rondônia, Pará, Amapá e Tocantins, sendo duas no Pará.
}

Revista Exitus, Santarém/PA, Vol. 10, p. 01-30, e020098, 2020. 


\section{Rumo ao interior da Amazônia: os projetos de interiorização iniciados pela UFPA}

O início da atuação da UFPA no interior do Estado se deu a partir de 1970, com a aprovação pelo Conselho Federal de Educação do Parecer $n^{\circ}$ 663/1970, que previa a instalação de Núcleos de Educação vinculados ao então Centro de Educação da Universidade. Esses Núcleos de Educação "foram coordenados por professores designados pelo reitor da época, o professor Doutor Aloísio da Costa Chaves" (COSTA, 2014, p. 224).

Foram instalados pela UFPA cinco Núcleos de Educação em municípios-sede do Estado do Pará: Abaetetuba, Castanhal, Marabá, Santarém e Soure e englobavam quatorze microrregiões do Estado (Ver localização das cidades polo na Figura 2).

Figura 2 - Mapa do Pará com as cinco cidades-sede, marcadas com círculos, onde foram instalados os Núcleos de Educação da UFPA no primeiro momento da interiorização

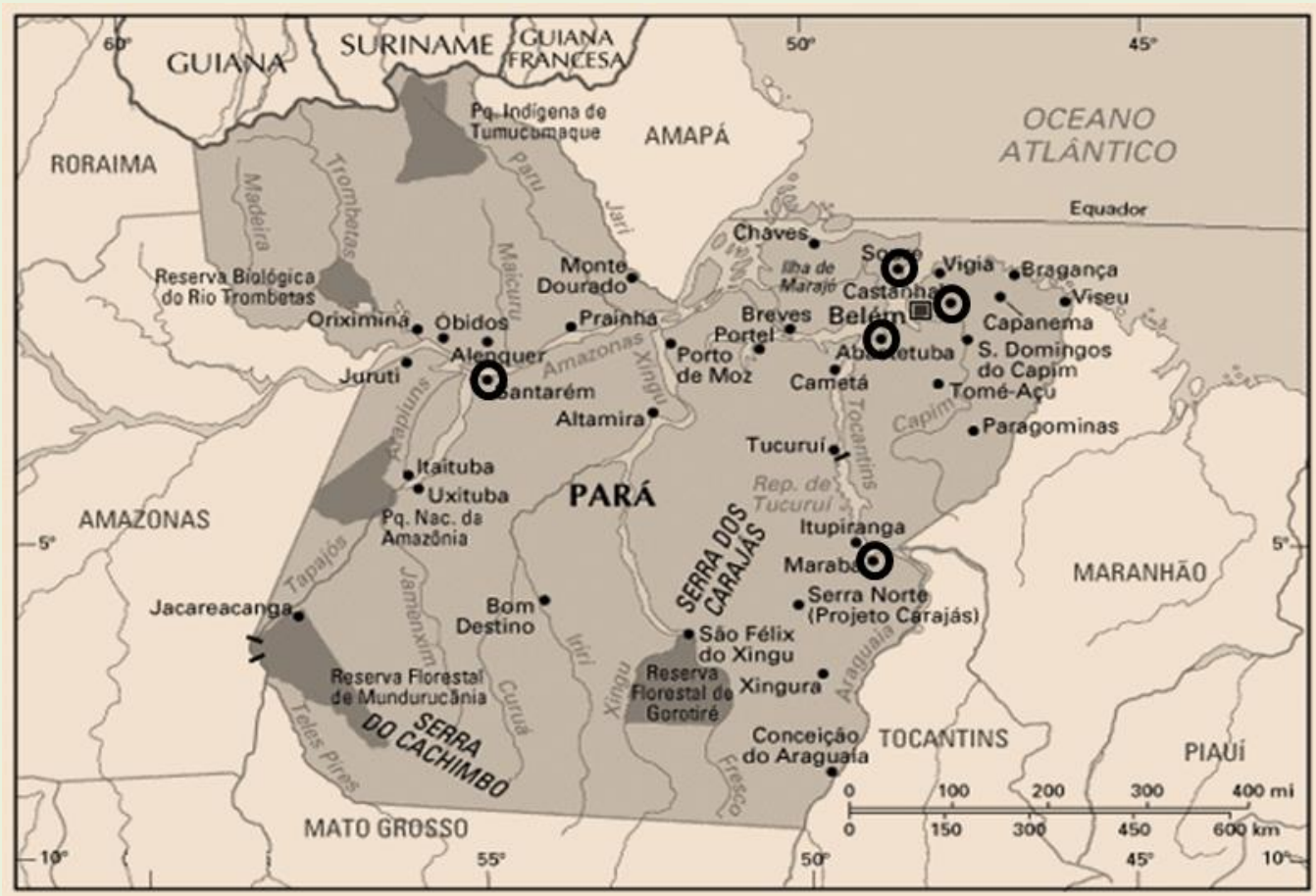

Fonte: guianet.com (com adaptações).

Cursos de licenciatura curta em regime intervalar8 foram os primeiros a

8 As Licenciaturas curtas foram propostas em caráter experimental e emergencial em 1964

Revista Exitus, Santarém/PA, Vol. 10, p. 01-30, e020098, 2020. 
serem oferecidos, pois a demanda por professores com nível superior no Pará apresentava altos índices, e no interior do Estado o déficit de docentes capacitados atingia índices alarmantes. O oferecimento desses cursos pioneiros de Licenciatura de curta duração em regime intervalar já seguia um modelo nacional de atividades extensionistas 9 em parceria com 0 Ministério da Educação (MEC).

Para o funcionamento dos Núcleos da UFPA nos municípios afastados da capital foram firmados convênios com o Governo do Estado do Pará, Governo do Território Federal do Amapá 10 e Delegacia Estadual do Ministério da Agricultura. As parcerias com as Secretarias Municipais e Estaduais de Educação, bem como com a iniciativa privada, foram muito importantes no processo quanto a "recursos financeiros, instalações e equipamentos dos prédios, indicação do pessoal de apoio, construção de prédio próprio e passagens para visitas de inspeção" (COSTA, 2014, p. 224).

Em Santarém, o Núcleo de Educação foi fundado em $1970^{11}$ e teve o início do funcionamento de suas primeiras turmas em 1971, com oferta de Licenciaturas curtas para formação de professores que atuavam na rede pública no primeiro ciclo do ensino primário, com habilitação em Administração Escolar (CARVALHO, 2014). As aulas da Universidade funcionavam na Escola Estadual Álvaro Adolfo da Silveira, o que foi possibilitado pela parceria da UFPA com o Governo do Estado e a Prefeitura

em virtude da enorme carência de professores (NASCIMENTO, 2012). A proposta era que elas fossem cursadas em 2 anos. Apesar de movimentos de resistências a elas, anos mais tarde essa modalidade de licenciatura ganha espaço na Lei $n^{\circ}$ 5692/71 (Lei de Diretrizes e Bases da Educação Nacional - LDB) e é regulamentada pela resolução n 30 de 11/07/1974, perdurando sua oferta até a promulgação da LDB de 96 (Lei n 9394/96). Quanto aos cursos intervalares estes eram oferecidos nos períodos de férias escolares, geralmente julho e janeiro.

9 Modelos do Centro Rural Universitário de Treinamento e Ações comunitárias (CRUTACs) e Centro Nacional de Aperfeiçoamento de Pessoal para a Formação profissional (CENAFOR Licenciaturas de Curta Duração).

10 O parecer aprovado em 1970 também previa o oferecimento de cursos pela UFPA ao então Território Federal do Amapá (COSTA, 2014), por isso surge o Convênio com o Governo do Amapá.

11 A fundação do Núcleo de Santarém ocorreu em "14 de outubro de 1970, por meio do Parecer $n^{\circ}$ 663/1970 do Conselho Federal de Educação (CFE) e da Resolução n 39/1970 do Conselho Superior de Ensino e Pesquisa (CONSEP), com a instituição dos Núcleos de Educação da UFPA" (CARVALHO, 2014. p. 91). 
do Município, já que o Núcleo de Educação em Santarém não possuía espaço próprio para funcionamento. Os cursos foram ofertados até 1973, mas, pelas precárias condições de funcionamento, parou de funcionar e só retomou suas atividades em 1980, por pressão popular e apoio político local, para a complementação dos que não haviam finalizado o curso e oferta de novas turmas.

Ainda em 1983 foi doado à UFPA pelo prefeito Ronan Liberal o prédio da Escola Municipal Everaldo Martins'12, ainda em construção na época (CARVALHO, 2014), para funcionar o Curso de Pedagogia, primeiro curso regular (não intervalar) fora da sede, criado em parceria entre a UFPA e a SUDAM - Superintendência de Desenvolvimento da Amazônia ${ }^{13}$ (UFPA, 2007; COSTA, 2014; CARVALHO, 2014). A professora Rosilda Wanghon foi a indicada como coordenadora desse curso e representou "a primeira coordenação dos serviços educacionais ofertados pela UFPA em Santarém, tornando-se a precursora das coordenações que no futuro viriam a compor o campus de Santarém" (CARVALHO, 2014, p. 93)14. Muitos alunos dessa primeira turma de Pedagogia tornaram-se docentes do campus da UFPA de Santarém posteriormente.

A UFSC que possuía um campus avançado em Santarém, como já mencionado em páginas anteriores, em 1986 acabou por transferir a infraestrutura e servidores que mantinha em Santarém para o campus de Santarém da UFPA, como indica Carvalho (2012)

(...) em janeiro de 1986, as administrações superiores da UFPA e da UFSC, realizaram uma reunião, em Santarém, para estabelecer critérios sobre a transferência à UFPA das instalações do Campus Avançado que a Universidade Federal de Santa Catarina mantinha no município. O processo de transição foi concluído no mesmo ano, pelo qual a infraestrutura e os servidores da UFSC passaram para a UFPA (p. 103).

\footnotetext{
12 Atualmente nesse local funciona o Instituto de Ciências da Educação da UFOPA.

13 SUDAM - Autarquia Federal vinculada ao Ministério da Integração Nacional criada pelo presidente militar Humberto de Alencar Castelo Branco, em 1965, com a "finalidade de dinamizar a economia amazônica, coordenar supervisionar e mesmo elaborar e executar programas e planos de outros órgãos federais" (COSTA, 2014. p. 178).

14 Trecho da Autorização para funcionamento do Campus de Santarém/UFPA redigida no ato do discurso de implantação pode ser encontrado na tese de Carvalho $(2014$, p. 96).
} 
Assim, nesse ano, o prédio cedido pela Prefeitura, juntamente com a infraestrutura cedida pela UFSC, agrupou as duas instituições, que passaram a funcionar o campus da UFPA em Santarém, distribuído em duas unidades:

(...) O chamado Campus I, atualmente conhecido como Campus Rondon, composto pela estrutura da Escola Municipal Everaldo Martins, que acolhia as salas de aulas e os setores da administração, a modesta biblioteca, uma reprografia e uma lanchonete; o Campus II, hoje chamado Campus Tapajós, acondicionava os alojamentos de professores e estudantes que desenvolviam atividades no Campus de Santarém (CARVALHO, 2014, p. 104).

Em 1986 o professor Aldo Gomes Queiróz foi nomeado coordenador do campus da UFPA/Santarém por meio da Portaria n 902 , de 14 de julho de 1986 e permaneceu no cargo até 2002 (CARVALHO, 2014), quando por meio de eleição tomou posse o professor de Física do campus de Santarém, Elinei Pinto dos Santos, que permaneceu no cargo até 2006.

O campus Universitário da UFPA em Santarém no final da década de 80 já era considerado um dos principais polos da UFPA no interior do Estado, como indicam algumas reportagens de jornais locais desta década. No entanto, as condições de funcionamento ainda eram precárias tanto em infraestrutura quanto de material humano (docentes e funcionários). Os docentes que ministravam aulas nos primeiros cursos da instituição, por exemplo, necessitavam deslocar-se da capital para o interior do Estado, pois o Núcleo não possuía corpo docente próprio para atender a demanda.

Diante desse contexto, é importante destacar que a UFPA iniciou seu processo de expansão para o interior do Estado sem apoio do poder público federal, o que não se deu desprovido de críticas e discussões por setores e profissionais da própria universidade, especialmente quanto à falta de recurso, mas a proposta foi amplamente apoiada pelos alunos e por professores das licenciaturas e aos poucos foi ganhando adeptos (FONTES, 2012).

Somente na década de 90 após a constatação da situação do Norte do país é que o MEC passou a disponibilizar verbas no orçamento da UFPA 
para o processo de interiorização da instituição ${ }^{15}$. Antes desse recurso, a Universidade usou sua autonomia orçamentária para disponibilizar verbas para a interiorização e o apoio das prefeituras foi fundamental para a continuidade e sucesso do processo, como ressalta Fontes (2012) ao fazer uma pesquisa com participantes da interiorização da UFPA.

Foi possível organizar um planejamento voltado à interiorização, de modo que a UFPA pagava aos docentes que iam ministrar aulas no interior com diárias e passagens, enquanto as prefeituras locais cediam casas ou hotéis para os professores. A diária acabava saindo como estímulo aos docentes.

O professor Nilson Oliveira lembra que os convênios feitos com as prefeituras definiam que elas cederiam salas de escolas municipais, 0 alojamento de professores e a alimentação. Algumas prefeituras ajudavam os alunos com transporte até os polos e às vezes até com alimentação e diárias. A contribuição desses prefeitos não pode ser esquecida, tendo sido fundamental para o sucesso da interiorização (p. 101).

Valer-se de cursos intervalares e dispor de um sistema de diárias para o pagamento de professores foram as alternativas empregadas pela UFPA para promover inicialmente a interiorização, já que não havia possibilidade naquela ocasião de se estabelecer um quadro permanente de docentes nos campi (FONTES, 2012). Possivelmente essa dificuldade e falta de recurso foram os motivos que levaram essa instituição a adotar até a década de 90 não a criação, mas a alocação de vagas da Capital para o interior, como aponta Costa (2014, p. 198):

Chama a atenção o fato da expansão/interiorização da UFPA ter ocorrido via alocação de vagas da Capital para as turmas que funcionavam no interior porque, curiosamente, essas vagas eram reais para a instituição em Belém, mas eram vagas virtuais para o interior. Virtuais porque legalmente não havia universitários no Campus de Santarém, Castanhal ou de outro município-sede, ainda que todos os matriculados fossem alunos da UFPA. Em todos os Campus isso aconteceu da mesma forma. Mesmo a IFES tendo oficializado o seu Programa de Interiorização em 1986, somente a partir de 1990 essa condição começou a mudar, dando sinais de que a UFPA viera para ficar no interior.

Os convênios firmados especialmente com órgãos da Prefeitura e do

15 Informação disponível em: http://www.jornalbeiradorio.ufpa.br/novo/index.php/2011/131edicao-99--novembro/1273-memorias-e-historias-da-interiorizacao. Acesso em: 13 jan. 2020.

Revista Exitus, Santarém/PA, Vol. 10, p. 01-30, e020098, 2020. 
Estado, permitiram que funcionários fossem cedidos para o funcionamento da UFPA em Santarém. Dessa forma, os primeiros funcionários (técnicos) do Núcleo são cedidos principalmente pelas Secretarias de Educação do Estado e do Município, pois o primeiro concurso da UFPA no local só vai ocorrer no início da década de 90 , primeiro para docentes e posteriormente para técnicos.

Diante dos enormes desafios enfrentados para o oferecimento de cursos no interior do Estado e pressionada pelas cobranças das comunidades interioranas pela ampliação no número de vagas para as regiões afastadas da capital, a UFPA fez um balanço dos resultados iniciais da interiorização e começou a discutir internamente $O$ assunto em Seminários e Encontros. Como resultado desse processo, surgiu o Projeto de Interiorização da UFPA, aprovado pela Resolução nº 1.355 de 03/02/1986 do Conselho Superior de Ensino e Pesquisa - CONSEP, na gestão do reitor José Seixas Lourenço (1985-1989). Após dezesseis anos, a interiorização da UFPA tornava-se, enfim, uma Política Institucional. Entre 1985 e 1986 na gestão de José Seixas Lourenço, a UFPA trouxe à Santarém cursos de licenciatura em Pedagogia, Letras, História, Biologia e Matemática, além dos cursos de Bacharelado em Direito e em Sistema de Informação, estes últimos iniciados em 1995 (BRASIL, 2009 apud CARVALHO, 2014).

O Projeto de Interiorização da UFPA ganhou apoio de outras IFES da Amazônia brasileira que passavam por necessidades e desafios semelhantes. Dados de um estudo realizado pelo Ministério da Educação (MEC) em 1985 apontavam que essa região possuía a menor taxa de universitários/1.000 habitantes $(4,7)$, enquanto o Nordeste estava com taxa de 5,8; Sudeste com 12,9; Sul com 13,1.

Assim, foi organizado um projeto de maior amplitude, que contemplava as propostas das nove IES envolvidas, o I Projeto Norte de Interiorização (I PNI - 1986-1989). Quanto às prioridades do projeto:

O I PNI estabeleceu como prioridade a realização de ações voltadas à formação de professores de $1^{\circ}$ e $2^{\circ}$ graus (Lei 5692/1971), definindo como relevante aquelas (sic) ações direcionadas ao resgate 
histórico e a preservação do patrimônio artístico e cultural do Estado e da região onde estava localizado o polo-regional e as voltadas para orientar a realização de pesquisas aplicadas. Propôs a implantação de vinte e cinco (25) Campus Universitários no interior dos Estados da Região Amazônica, com vistas à realização de cursos de graduação (Licenciaturas), reciclagem e capacitação, projetos artísticos e culturais, projetos de pesquisa aplicada, treinamento e assessoramento às comunidades e suas populações (I PNI apud COSTA, 2014, p. 227).

Participavam desse primeiro projeto a Fundação Universidade Federal do Acre, Fundação Universidade Federal do Amapá, Fundação Universidade Federal do Amazonas, Fundação Universidade Federal do Maranhão, Fundação Universidade Federal do Mato Grosso, Fundação Universidade Federal do Pará, Fundação Universidade Federal de Roraima, Fundação de Ciências Agrárias do Pará e Universidade Federal de Rondônia (COSTA, 2014).

A partir do I PNI a UFPA passou a se instalar permanentemente nos Polos Universitários ${ }^{16}$, nos quais foram criados os oito primeiros campi universitários, nas seis mesorregiões paraenses, distribuídos em municípios estratégicos geograficamente e de melhores condições socioeconômicas: Abaetetuba, Altamira, Bragança, Cametá, Castanhal, Marabá, Santarém e Soure ${ }^{17}$. É nesse período que o Núcleo de Educação da UFPA de Santarém fica responsável pela Mesorregião do Baixo Amazonas e é transformado em campus Universitário de Santarém (UFPA, 2007; COSTA, 2014).

Apesar do esforço das IFES Amazônicas para a ampliação do número de vagas e atendimento às populações afastadas dos grandes centros, dados oficiais do MEC na década de 90 mostravam que o ensino superior no Norte ainda era inexpressivo. Segundo essa nova pesquisa, enquanto no Brasil, 10 a cada 100 jovens entre 18 e 24 anos estavam cursando uma

\footnotetext{
16 Um Polo Universitário é caracterizado como um território de atuação da Universidade que reúne identidade histórica e cultural da população e onde se desenvolvem atividades econômicas que possibilitam a projeção comum para vários municípios ou regiões. Os Polos Universitários podem ser constituídos de Campus(i) e/ou Núcleo(s) (COSTA, 2014, p. 195. Definição amparada em Documentos oficiais da UFPA).

17 O leitor poderá perceber que houve uma ampliação no número de municípios se comparar com a instalação dos primeiros Núcleos da UFPA já anteriormente citados. Eram cinco municípios polos dos Núcleos e passaram a ser oito para a instalação dos campi. Santarém sempre esteve entre eles.
} 
Universidade, no Pará essa média caía pela metade (5 universitários a cada 100 jovens). No interior do Estado essa média era muito pior, 1 universitário para cada 100 jovens (UFPA, 2000) 18 .

Entre 1986 e 1993, como resultado do I Projeto Norte de Interiorização, a UFPA ofereceu 187 cursos de licenciatura fora da sede, sendo 158 de Licenciatura Plena e 25 de Licenciatura Curta. 54\% desses cursos eram oferecidos em períodos intervalares, enquanto $46 \%$ em períodos regulares. Quanto ao número de vagas ofertadas por todas as Universidades Amazônicas participantes do Projeto, este chegou a 8.520 (COSTA, 2014, p. 191). Pelos motivos já anteriormente apontados de déficit de professores e impossibilidade financeira de se criarem outros cursos, as licenciaturas eram prioritárias.

Como o I PNI havia trazido consequências positivas para a região e suas Universidades, as IFES perceberam que era necessário o projeto ser ampliado, dadas as peculiaridades dos interiores dos Estados, e a necessidade de superar $\circ$ analfabetismo e universalizar $\circ$ ensino fundamental, como previa a Constituição de 1988.

Assim, em dezembro de 1993 ocorreu em Santarém o "Seminário de Avaliação e perspectivas da Interiorização das Universidades Amazônicas", que reuniu resultados de reuniões ocorridas em Rio Branco (AC), Belém (PA) e Porto Velho (RO), sobre o processo de interiorização das IFES da Amazônia e culminou com a criação do II Projeto Norte de Interiorização (II PNI, 19941997). Costa (2014) discute que diferentemente de outros Projetos voltados à formação superior, o II PNI não derivou de uma decisão governamental, mas sim da iniciativa das IFES da Amazônia diante dos resultados do primeiro projeto.

Quanto às principais realizações do II PNI tem-se:

Continuação da oferta de Cursos de Licenciatura Curta e Plena para formação de professores de $1^{\circ}$ e $2^{\circ}$ Graus; 2) Cursos de pósgraduação "latu" e "strictu sensu"; 3) Cursos de reciclagem; 4) Cursos

18 A referência dessa informação é um projeto este elaborado pela comunidade acadêmica local para dar subsídio para a independência do Campus de Santarém (UNIVERSIDADE FEDERAL DO PARÁ, 2000). 
de capacitação; 5) Projetos Artísticos-Culturais; 6) Projetos de Pesquisa através de ações simplificadas e de grande retorno para a compreensão da Região; 7) Projetos de Trabalho para a formação de uma consciência crítica da realidade; 8) Treinamentos; e 9) Assessoramentos. Para este fim foram estabelecidas parcerias, alianças e acordos, sendo tomadas medidas estratégicas para viabilização da Interiorização da ES na Amazônia (COSTA, 2014, p. 229).

Para a viabilização dessas ações, as IFES contaram com o apoio de alguns Ministérios; da SUDAM; SUFRAMA ${ }^{19}$, bem como do Projeto Rondon e Secretarias de Governo (Ibidem, p. 229-230). Com a criação e ampliação de vagas para professores efetivos do campus de Santarém resultado do sucesso conquistado no II Projeto Norte, este passa a ofertar os cursos de Direito (bacharelado), Tecnologia em Processamento de Dados (bacharelado) e Biologia (bacharelado) (CARVALHO, 2014).

Em 1997 como resultado da primeira década o campus amplia o número de vagas e cursos em caráter intensivo e de pós-graduação em Santarém e outros municípios do oeste do Pará.

Finalizando a primeira década de funcionamento, em 1997, o Campus de Santarém expande sua área de atuação e oferta, em caráter intensivo, os cursos de Física, Química, Ciências Sociais, História, Geografia e Letras com Habilitação em Língua Inglesa (Santarém), além dos cursos de Letras oferecidos nas cidades de Itaituba e Monte Alegre, e Pedagogia em Óbidos. Esses cursos garantiram a oferta de aproximadamente 255 vagas à população local. Posteriormente, de maneira gradativa, foram oferecidos cursos em nível lato sensu (especialização) em: Biologia, Matemática e Física; Métodos Computacionais no Ensino de Ciências; Informática no Ensino de Ciências e Matemática; Educação Especial; Língua Portuguesa com ênfase em abordagem textual; Docência no Ensino Superior; História da Amazônia; Educação Ambiental; Ciências Ambientais; Planejamento do Desenvolvimento Regional (CARVALHO, 2014, p. 105).

Seguiu-se ainda o III Projeto Norte de Interiorização (1998-2001) para fortalecer e complementar as ações dos projetos I e II. Já o quarto projeto esteve voltado para a pesquisa e pós-graduação e visava atender à demanda de docentes lotados nos campi e profissionais formados pelas Instituições de ensino Superior (IES) que almejavam formação ao nível de

\footnotetext{
19 Superintendência da Zona Franca de Manaus.
} 
pós-graduação, e na época necessitavam se deslocar para os Centros urbanos em busca dessa capacitação. A criação desse quarto projeto era uma estratégia para reduzir a evasão de profissionais qualificados que estavam contribuindo com o ensino local e regional.

Carvalho (2014) ressalta que a descentralização do ensino superior federal no Pará se confunde com a própria história da UFPA e o processo de interiorização representou a primeira tentativa "de implantação de uma instituição de ensino superior no Oeste Paraense" (p. 91). Para a consolidação do processo de interiorização da UFPA os professores substitutos também foram fundamentais. Entre 1993-1996, por exemplo, eles formavam a grande maioria de professores do campus da UFPA-Santarém, como indica o Projeto de Transformação do campus Universitário da UFPA de Santarém em Centro Universitário Federal do Tapajós (UFPA, 2000). Fontes (2012) constata em sua pesquisa que a interiorização da UFPA gerou muitas discussões não registradas ou detalhadas em documentos, mas, com base no discurso apresentado por seus informantes, percebeu que há uma memória coletiva a partir da qual "todos os segmentos sociais que participaram do processo de interiorização avaliam hoje que foi necessário e importante para a implantação da UFPA no estado o projeto de interiorização" (FONTES, 2012, p. 96).

A expansão de novas vagas para o ensino superior público no Pará através da interiorização levou a UFPA a ser considerada, por vários anos, a maior IFES em número de alunos matriculados. Quanto ao campus de Santarém, entre 1988 e final de 2000, já havia formado 1.088 profissionais em nível superior (UFPA, 2000, p. 19). Sabe-se que esses números não representam necessariamente qualidade na formação de todos esses profissionais oriundos da interiorização, mas é inegável que a UFPA formou ao longo dos anos não somente profissionais para o ensino básico, mas também para o ensino superior, que muito contribuem com a educação em Santarém e toda a região Oeste do Pará. A exemplo disso muitos professores formados em cursos de interiorização atuam como docentes da Universidade Federal do Oeste do Pará (UFOPA), esta criada a partir do 
Campus da UFPA em Santarém.

O campus de Santarém chegou ao ano 2000 como símbolo de ensino superior público no Oeste do Pará, com força política junto ao Conselho Superior da UFPA na capital e referência em termos de interiorização (CARVALHO, 2014). Em 1992 no Jornal "O Tapajós", o pró-reitor de extensão da UFPA, Prof. Alex Fiúza de Melo, já anunciava que "Santarém e a região Oeste do Pará sempre serão prioridades para a UFPA" (O OESTE,1992. p. 9) ${ }^{20 .}$ Na reportagem o pró-reitor ressalta que é necessário criar um espaço em Santarém onde a própria população do Oeste do Pará gere seus produtos acadêmicos e que não se reduza ao que o corpo docente de Belém oferece (ver reportagem na figura 3). Essas e muitas outras notícias da década de 90 mostram a importância que o Campus da UFPA teve para a região.

Um marco importante na história do campus da UFPA em Santarém foi a criação do curso de graduação Licenciatura em Física Ambiental. Esse curso "se iniciava com uma proposta inovadora na formação de licenciados em Física com vocação às discussões de problemáticas ambientais" (CARVALHO, 2014. p. 133) e com isso o campus foi incluído no Plano de expansão do Ministério da Educação e passou a receber recursos para implementar o curso e para ampliação do espaço físico ${ }^{21}$.

20 Os jornais utilizados na pesquisa fazem parte do Acervo da Biblioteca do Instituto Cultural Boanerges Sena, localizado em Santarém-PA.

${ }^{21}$ Esse curso infelizmente foi extinto com a criação da Universidade Federal do Oeste do Pará. 
Figura 3 - Reportagem do Jornal semanal "O Tapajós" indicando a importância que a UFPA atribuía a um campus universitário em Santarém-PA

- TAPAsOS. ftrm - PA. 24 a 28 de feerho de 1992 . p. 9

\section{O oeste do Pará sempre será prioridade para UFPa}
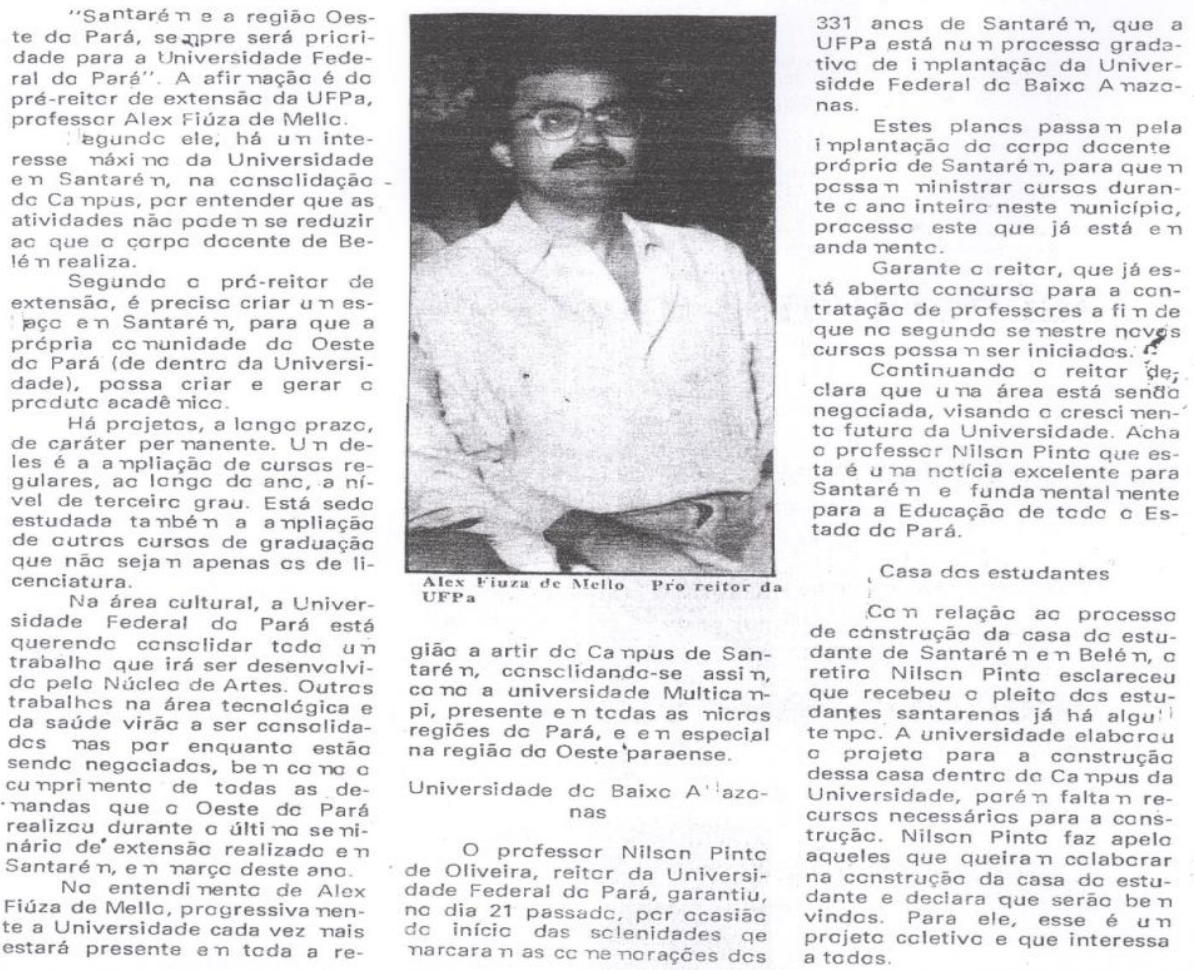

Fonte: O OESTE... (1992. p. 9).

É importante destacar que o Conselho universitário da Universidade Federal Rural da Amazônia (UFRA, antiga FCAP) em 2003 institui uma unidade descentralizada em Santarém "atendendo às reivindicações políticas que buscavam a integralização regional da referida área ao restante do Estado" e criou o curso de Graduação em Engenharia Florestal (CARVALHO, 2014, p. 128). A unidade UFRA/Tapajós funcionava no Campus II da UFPA Santarém, no espaço do antigo Centro de Tecnologia da Madeira da SUDAM, espaço esse hoje pertencente ao campus Tapajós da UFOPA. 


\section{A criação da UFOPA no oeste do Pará}

Considerando todo esse histórico de luta da comunidade local pela chegada do ensino superior na região Oeste do Pará, no final do ano 2000 uma Comissão foi formada pelo coordenador do Campus de Santarém, Prof. Aldo Gomes Queiroz, para criar um Plano de trabalho preliminar visando a implantação do Centro Universitário Federal do Tapajós (CARVALHO, 2014). Esse foi um dos documentos utilizados para a elaboração da narrativa aqui descrita (UNIVERSIDADE FEDERAL DO PARÁ, 2000), pois é fundamentado em dados referentes ao Campus Universitário de Santarém e seu processo de consolidação. Considera-se essa a primeira manifestação concreta que daria origem futuramente à criação da Universidade Federal do Oeste do Pará (UFOPA) (CARVALHO, 2014).

Em 2007 durante o XV Fórum de Coordenadores de campus da UFPA O então reitor, Prof. Dr. Alex Fiúza de Melo, anunciou maior possibilidade de criação de uma universidade no interior do Estado do Pará, mas ainda havia incerteza quanto ao município onde seria instalada.

Em 5 de março de 2007, em Belém, durante o referido XV Fórum de Coordenadores de Campi, o reitor da UFPA, Prof. Alex Bolonha Fiúza de Melo, anunciou a intenção do Presidente da República, Luís Inácio Lula da Silva, e do Ministro da Educação, Fernando Haddad, de criar e implantar uma nova universidade no interior da Amazônia, e que, em decorrência de argumentos apresentados pelo reitor da UFPA ao ministro da Educação, essa universidade seria instalada no interior do estado do Pará, estando a disputa entre Santarém e Marabá (CARVALHO, 2014, p. 135-136).

Esse anúncio levou a coordenadora do Campus de Santarém, professora Marlene Escher Furtado22, a iniciar uma intensa mobilização na região Oeste do Estado. Mas "O maior desafio era trazer essa nova universidade para Santarém, o que só se conseguiria com o apoio da sociedade e das lideranças políticas do estado do Pará" (CARVALHO, 2014, p. 138). Interesses políticos e econômicos também estavam em jogo e por

22 Gestão de 2006 a 2009.

Revista Exitus, Santarém/PA, Vol. 10, p. 01-30, e020098, 2020. 
isso a atuação e articulação dos atores institucionais e políticos fizeram diferença na tramitação e posterior aprovação do Projeto de Lei de criação da nova Universidade (GOMES, 2011). Carvalho (2014) e Gomes (2011) ressaltam que antes do envio do projeto ao Congresso Nacional ocorreram intensos debates, organização de documentos, articulações políticas e por fim

(...) o projeto de criação da UFOPA foi encaminhado ao Congresso Nacional em 12 de dezembro de 2007, por meio de mensagem presidencial. O projeto de criação da UFOPA, Lei $n^{\circ} 2.879 / 09$, de iniciativa da Presidência da República, tramitou no Congresso Nacional de janeiro de 2008 a novembro de 2009, sendo sancionado pelo Presidente da República em exercício, José Alencar, no dia 5 de novembro de 2009, em Brasília" (CARVALHO, 2014, p. 149).

A Universidade Federal do Oeste do Pará (UFOPA) foi criada como uma instituição multicampi pela Lei $n^{\circ} 12.085$ de 05 de novembro de 2009. É considerada a primeira Universidade federal com sede no interior da Amazônia brasileira (fora das capitais), localizada no município de SantarémPA, o terceiro maior município do Estado. Sua estrutura inicial incorporou os campi da UFPA e da UFRA que já existiam na cidade, além de outras unidades dessas instituições para a formação dos campi de Alenquer, Itaituba, Juruti, Monte Alegre, Óbidos e Oriximiná. A criação dessa nova Universidade fez parte do Programa de Reestruturação e expansão das Universidades Federais (REUNI) do governo Federal e pretendia ser a Universidade de Integração da Amazônia (BRASIL, 2012), como já sinalizado em páginas anteriores.

Dessa forma, percebemos que a chegada da UFOPA em Santarém foi reflexo da conquista de quase 40 anos de movimento pelo ensino superior federal de qualidade no interior do Estado do Pará.

\section{Considerações finais}

A chegada e permanência do ensino superior em Santarém se confundem com a história da UFPA na região. Foi possível perceber que a UFPA teve grande influência na oferta de vagas em municípios fora das capitais dos Estados da Amazônia brasileira, influenciado pelo I Projeto de 
interiorização da UFPA, o que levou à construção dos Projetos Norte de interiorização envolvendo várias instituições federais amazônicas do ensino superior. Mas também foi possível perceber que a chegada do ensino superior na Amazônia está relacionada a interesses políticos e econômicos dos governantes, seja no âmbito Estadual, seja no Nacional.

O programa de Interiorização da UFPA, os incentivos financeiros do governo federal, mas, principalmente, a organização política da sociedade civil e comunidade acadêmica do campus de Santarém, em articulação com os políticos locais, tornaram concreto o sonho de ingresso a uma universidade federal para muitos jovens do Oeste do Estado do Pará.

A população dessa região, em virtude do difícil acesso para a capital, há décadas almejava cursos ofertados por uma Universidade pública federal, o que em parte foi suprido com os campi criados pela UFPA e pela UFRA, em Santarém e em outros municípios do Baixo Amazonas, frutos do movimento de interiorização dessas instituições, que deram origem à UFOPA 23 .

Os sujeitos participantes do processo foram de extrema importância para que o projeto de interiorização do ensino superior no Pará se concretizasse. Nas palavras de Fontes (2012, p. 113) "A interiorização foi sendo construída e repensada, através das experiências de reitores, professores, alunos e funcionários. Portanto, a UFPA se tornou multicampi não apenas por seus campi mas também pela diversidade de sujeitos que participaram desta construção". E a UFOPA, apesar das controvérsias que

\footnotetext{
23 É importante destacar que além dessas universidades federais, a Universidade do Estado do Pará (UEPA), criada em 1993, chegou a Santarém em outubro de 1998 com o curso de Educação Física e posteriormente criou o curso de Música, Enfermagem, Fisioterapia e, em 2006, Medicina. Faculdades privadas também se fazem presentes na região, como a Universidade Luterana do Brasil - ULBRA, Faculdades Integradas do Tapajós - Fit (atual Universidade da Amazônia - Unama) e Instituto Esperança de Ensino superior - IESPES, subsidiadas por associações mantenedoras. "Tais faculdades implantaram cursos que são considerados básicos quanto à instalação de serviços essenciais à população, como: enfermagem e formação de professores, por conta da demanda das prefeituras circunvizinhas; e direito e administração em gestão pública, com a intenção de atender às secretarias estaduais e municipais" (CARVALHO, 2014, p. 81).
} 
permeiam sua criação e consolidação no Oeste do Estado do Pará24, representa uma grande conquista para a região.

\section{REFERÊNCIAS}

BARBOSA, R. R.; LOPES, A. P. C. Uma historiografia da reforma universitária de 1968. In: JORNADA DO HISTEDBR, 9, 2010, Belém, PA. Anais eletrônicos [...]. Disponível em:

http://www.histedbr.fe.unicamp.br/acer_histedbr/jornada/jornada9/trabalho s.html. Acesso em: 27 jan. 2015.

BOGDAN, R.; BIKLEN, S. Investigação qualitativa em educação. Porto, Portugal: Porto, 1994.

BRASIL. Ministério da Educação. Análise sobre a Expansão das Universidades Federais 2003 a 2012: volume 1. Brasília, DF: MEC, 2012. Disponível em: http://portal.mec.gov.br/index.php?option=com_docman\&view=download\&alias=12386analise-expansao-universidade-federais-2003-2012-pdf\&ltemid=30192. Acesso em: 24 jun. 2019.

CARVALHO, E. N. A interiorização do ensino superior na Amazônia: o caso de Santarém no Oeste do Pará: 1985 a 2010. Tese (Doutorado em Geografia) Universidade Estadual do Ceará, Centro de Ciências e Tecnologia, Ceará, 2014. Disponível em:

http://www.vece.br/mag/dmdocuments/ednea_do_nascimento_carvalho_tese201 1_.pdf. Acesso em: 20 jun. 2019.

COSTA, M. R. S. As repercussões da interiorização da UFPA no trabalho dos docentes da rede estadual de ensino no Pará nas décadas de 1980 e 1990. Tese (Doutorado em Educação) - Universidade Federal do Pará, Instituto de Ciências da Educação, Belém, 2014. Disponível em:

http://repositorio.ufpa.br/jspui/bitstream/2011/6708/1/Tese_RepercussoesInteriorizacaoufPA .pdf. Acesso em: 15 abr. 2020.

DIAS, A. L. B.; COELHO, M. S.; SANTOS, F. A. F. A Política de Interiorização da Universidade Federal do Pará no Município de Cametá - PA. Olhar de professor, Ponta Grossa, PR, v. 7, n. 2, p. 35-46, 2004. Disponível em: https://www.revistas2.uepg.br/index.php/olhardeprofessor/article/view/1401/1046. Acesso em: 03 jun. 2016.

${ }^{24}$ Posso destacar como duas principais controvérsias à consolidação da UFOPA o fato dela já ser criada multicampi e com uma proposta interdisciplinar, o que levou a discussões acaloradas da comunidade acadêmica nos primeiros anos de sua consolidação. Há quem argumente também que o projeto de criação da UFOPA diferiu muito daquele pensado anteriormente pela comunidade acadêmica que iniciou os trabalhos com o documento Projeto de transformação do Campus Universitário de Santarém no Centro Universitário Federal do Tapajós (UFPA, 2000). 
FONTES, E. J. O. Memória e história da interiorização da UFPA: quando a memória constrói uma história coletiva. Fronteiras: Revista Catarinense de História [on-line], Santa Catarina, v. 20, p. 93-114, 2012. Acesso em: 20 jun. 2019.

GOMES, I. C. C. O processo de criação de uma universidade para a Amazônia: os bastidores da criação da UFOPA. Dissertação (Mestrado em Desenvolvimento Sustentável do Trópico Úmido) - Universidade Federal do Pará, Núcleo de Altos Estudos Amazônicos, Belém, 2011 . Disponível em: http://repositorio.ufpa.br/jspui/bitstream/2011/2934/1/Dissertacao_ProcessoCriacaoUniversi dade.pdf. Acesso em: 29 jun. 2019.

LIMA, N. M. F. Ensino superior na Amazônia: desafios e possibilidades do ensino superior na região Norte. In: JORNADA INTERNACIONAL POLÍTICAS PÚBLICAS, 7., 2015, São Luiz, MA. Anais eletrônicos [...]. Disponível em: http://www.joinpp.ufma.br/jornadas/joinpp2015/pdfs/eixo13/ensino-superiorna-amazonia-desafios-e-possibilidades-do-ensino-superior-na-regiaonorte.pdf. Acesso em: 30 jun. 2019.

LUDKE, M.; ANDRÉ, M. E. D. A. Pesquisa em educação: abordagens qualitativas. São Paulo: EPU,1986.

MACULAN, N. Expansão Brasil universitário: Programa de expansão da educação superior. Apresentação para a Câmara dos Deputados em 20/06/2006. Disponível em: https://slideplayer.com.br/slide/355415/. Acesso em: 30 jun. 2019.

MARTINS, C. B. A reforma universitária de 1968 e a abertura para o ensino superior privado no Brasil. Caderno Educação e Sociedade, Campinas, v. 30, n. 106, p. 15-35, 2009. Disponível em: http://www.scielo.br/pdf/es/v30n106/v30n106a02. Acesso em: 12 fev. 2015.

MORAES, M. C. M. Educação e política nos anos 30: a presença de Francisco Campos. Revista Brasileira de Estudos Pedagógicos, Brasília, v. 73, p. 17-4, 291-321, 1992.

NASCIMENTO, T. R. A criação das licenciaturas curtas no Brasil. Revista HISTEDBR On-line, Campinas, v. 12, n. 45, p. 340-346, 2016. Disponível em: https://doi.org/10.20396/rho.v12i45.8640153. Acesso em: 20 abr. 2020.

O OESTE do Pará sempre será prioridade para UFPA. Jornal O Tapajós. Santarém, 1992, s/n, p.9, 24 a 28 jun. 1992.

PONTE, J. P. Estudo de caso em educação matemática. Boletim de Educação Matemática (Bolema), Rio Claro, SP, v. 25, p. 105-132, 2006. Disponível em: http://repositorio.ul.pt/bitstream/10451/3007/1/06-Ponte\%28BOLEMAEstudo\%20de\%20caso\%29.pdf. Acesso em: 29 mar. 2016. 
UNIVERSIDADE FEDERAL DO PARÁ (UFPA). Plano de gestão 2007 - 2011: UFPA Campus de Santarém. Santarém-PA: Campus de Santarém, 2007.

UNIVERSIDADE FEDERAL DO PARÁ (UFPA). Projeto de transformação do Campus universitário de Santarém no Centro Universitário Federal do Tapajós. Santarém-PA: Campus de Santarém, 2000.

VASCONCELOS, I. M. A Federalização do ensino superior no Brasil. Dissertação (Mestrado em Sociologia) - Universidade de Brasília, Departamento de Sociologia, Brasília, 2007. Disponível em:

http://repositorio.unb.br/bitstream/10482/2525/1/2007_IsamaraMartinsVasconcelos.pdf. Acesso em: 26 jan. 2014.

YIN, R. K. Estudo de caso: planejamento e métodos. 2. ed. Porto Alegre: Bookman, 2001.

Recebido em: 13 de maio de 2020 Aprovado em: 29 de setembro de 2020 Publicado em: 08 de outubro de 2020 